\title{
PARA SABER O QUE O PÚBLICO PENSA SOBRE ARQUEOLOGIA...
}

\author{
Marília Xavier Cury*
}

\begin{abstract}
Resumo: 0 presente estudo se desenvolveu entre 2003 e 2005 no Museu Água Vermelha de arqueologia regional, em Ouroeste, estado de São Paulo, Brasil. Consistiu na tese de doutorado intitulada Comunicação Museológica - Uma Perspectiva Teórica e Metodológica de Recepção, defendida na Escola de Comunicações e Artes da Universidade de São Paulo. ${ }^{1}$

Neste texto, apresentamos para discussão alguns aportes da pesquisa de maneira sintética e parcial.

A pesquisa se sustentou teórica e metodológicamente nas áreas de museologia, comunicação e recepção. Quanto à museologia, foram focadas essencialmente a expologia, expografia e educação patrimonial.
\end{abstract}

Palavras-chave: Comunicação da arqueologia - Comunicação museológica - Exposição arqueológica. Educação patrimonial - Avaliação museológica.

\section{Introdução - A descoberta arqueológica}

No ano de 1997, às margens do rio Grande e junto à Usina Hidrelétrica Água Vermelha - município de Ouroeste, Estado de São Paulo - foram achados vários sepultamentos humanos, posteriormente identificados como pré-coloniais ${ }^{2} \mathrm{~A}$ descoberta gerou duas campanhas arqueológicas entre 1997 e $1998^{3}$ e a pesquisa de-

(*) Museu de Arqueologia e Etnologia da Universidade de São Paulo - maxavier@usp.br

(1) Sob a orientação da Profa. Dra. Maria Immacolata Vassallo de Lopes.

(2) A identificação foi feita pela arqueóloga Maria Lucia Pardi.

(3)O início dos trabalhos deu-se a partir do contrato firmado entre a CESP e o MAE/USP (Contrato MMA/ CESP - MAE/USP - 001/97) e da autorização do IPHAN concedida na Portaria 43, publicada no Diário Oficial da União em 24/9/1997. senvolvida por uma equipe interdisciplinar - antropólogos físicos, zooarqueólogos, geoarqueólogos, arqueólogos especialistas em grupos ceramistas e caçadores-coleto$\mathrm{res}^{4}$ - revelou uma situação arqueológica complexa e inédita, o que deveria ser devidamente explorado.

Em 2002, sob a mediação do Ministério Público Federal, foi firmado o TAC-Termo de Ajustamento de Conduta pelo prefeito municipal de Ouroeste e por representantes do IPHAN-Instituto do Patrimônio Histórico e Ar-

(4) São eles: Profs. Drs.: Erika Marion RobrahnGonzález, coordenadora e especialista em grupos ceramistas; Marisa Coutinho Afonso, geoarqueóloga; Paulo Antonio Dantas De Blasis, especialista em grupos caçadores-coletores; Levy Figuti, zooarqueólogo; Eduardo Goes Neves, especialista em grupos ceramistas; e Sabine Eggers, antropóloga física. 
tístico Nacional, Ministério da Cultura, ${ }^{5}$ e da A. E. S. Tietê S. A. ${ }^{6}$

De acordo com o TAC, várias ações deveriam ser tomadas quanto à preservação $\mathrm{e}$ comunicação do acervo arqueológico. Em síntese, promover o salvamento e monitoramento arqueológico, criar um museu de arqueologia regional, criar projeto de lei para uma Política Municipal de Preservação do Patrimônio Arqueológico.

O Museu de Arqueologia e Etnologia da USP foi, então, convidado para o desenvolvimento do salvamento arqueológico ${ }^{7} \mathrm{e}$ para a concepção e implantação daquele que passou a ser chamado de Museu Água Vermelha. ${ }^{8}$

Após a assinatura do TAC foi realizada mais uma etapa de escavação e a análise arqueológica em laboratório. Em paralelo, deu-se início aos trabalhos museológicos para a plena instalação do museu.

No dia 2 de setembro de 2003 foi inaugurado o Museu Água Vermelha e a exposição de longa duração Ouroeste: 9 Mil Anos de História.

\section{Apresentação - Da arqueologia à museologia}

A pesquisa arqueológica nos sítios Água Vermelha transcorreu em alguns anos - entre as etapas de escavação, a análise laboratorial e a redação de relatórios cientí-

(5) A arqueóloga Maria Lucia Pardi.

(6) The AES Corporation adquiriu o controle acionário da CESP em 27/10/1999 em função do Programa Estadual de Desestatização. A Usina Hidrelétrica Água Vermelha é uma das 10 que compõem a AES Tietê S. A., uma das empresas geradoras do grupo AES Corporation.

(7) Os arqueólogos responsáveis foram os Profs. Drs.: Paulo Antônio Dantas De Blasis e Erika Marion Robrahn-González. O primeiro é pesquisador do MAE/ USP e a segunda é colaboradora da empresa Documento Antropologia e Arqueologia.

(8) O projeto museológico foi coordenado pela Profa. Dra. Marilia Xavier Cury, museóloga do MAE/USP. ficos. Esses anos de trabalho, sem dúvida, resultaram em uma base científica consistente para a aplicação museológica e, em decorrência disto, a criação de um museu comprometido com a população regional. Como conseqüência - e porque não poderia ser de outra forma - buscamos apoio às bases concernentes ao nível de profissionalização que uma instituição museológica contemporânea exige.

Independentemente do porte físico do Museu Água Vermelha - $250 \mathrm{~m}^{2}$ - a equipe de museologia ${ }^{9}$ buscou o aporte museológico condizente com a relevância arqueológica e com a responsabilidade social que o museu passaria a ter na região.

As ações museológicas foram estruturadas a partir da operação do processo curatorial - (a) aquisição do acervo; (b) pesquisa, conservação, documentação museológica; (c) comunicação (exposição e educação) $^{10}$ - e compreenderam diversos aspectos e um cronograma: (1) elaboração da estimativa orçamentária - novembro de 2000; (2) realização e discussão do programa arquitetônico ${ }^{11}$ - março de 2001; (3) conclusão do projeto museológico-institucional ${ }^{12}$ abril de 2001; (4) elaboração dos sub-projetos para reserva técnica e para documentação museológica e da história institucional maio de 2002 a março de 2003; (5) avaliação técnica do edifício em construção - setembro de 2002; (6) instalação da reserva técnica e implantação do sistema de documentação - março de 2003; (7) treinamento

(9) Formamos a Equipe de Gestão Museológica composta por Ana Carla Alonso, Aureli Alves de Alcântara e Joana Montero Ortiz.

(10) A aquisição/coleta do acervo e a pesquisa ficaram a cargo da equipe de arqueologia, ao passo que as ações de conservação preventiva, documentação, exposição e educação ficaram sob a responsabilidade da equipe de museologia.

(11) A autora do projeto arquitetônico é Cássia Magaldi.

(12) As responsabilidades pelo projeto museológico e programa arquitetônico foram divididas com a Profa. Dra. Erika Robrahn-González, arqueóloga. 
de conservação preventiva e documentação ${ }^{13}$ - março de 2003; (8) elaboração dos subprojetos expositivo e educativo - maio a setembro de 2003; (9) avaliação conceitual ou pré-avaliação - março de 2003; (10) montagem da exposição e implantação do projeto educativo - maio a setembro de 2003; (11) treinamento sobre expografia e educação junho e setembro de 2003; ${ }^{14}$ (12)inauguração da exposição Ouroeste - 9 Mil Anos de História - 2 de setembro de 2003; (13) início do atendimento escolar - 3 de setembro de 2003; (14) avaliação da exposição - setembro a novembro de 2003; (15) conclusão da pesquisa de recepção da exposição ${ }^{15}$ - maio de 2005.

\section{A comunicação museológica no Museu Água Vermelha}

A exposição para um museu é a sua parte mais visível. É, também, o que torna uma instituição preservacionista um museu, isto porque um museu preserva e comunica. Não é possível, para um museu, prescindir de um acervo, mas o acervo não o torna museu, 0 que somente é possível com a comunicação e, especialmente, com a exposição. Não é possível, para uma exposição, prescindir do acervo, pois corre o risco de perder o seu status privilegiado de linguagem museológica. Nenhuma outra linguagem alcança ser aquilo que a exposição museológica é.

A dinâmica de um museu opera a partir do processo museológico e este não é linear. Ao contrário, é cíclico e, além disto, uma ação intervém na outra. Sendo um sistema, valeria a pena pensar este processo em sua di-

(13) A partir de 2003 a Prefeitura de Ouroeste indicou três funcionários para cuidar do museu. Eles foram treinados pela equipe de museologia do MAE.

(14) Todas as ações foram desenvolvidas pela Equipe Gestão Museológica.

(15) A pesquisa de recepção faz parte de CURY, Marília $X$. Comunicação museológica - Uma perspectiva teórica e metodológica de recepção, tese defendida em maio de 2005. mensão sinérgica, quando cada uma de suas ações age simultaneamente sobre as outras. O processo curatorial é a cadeia operatória cíclica que compreende a formação do acervo, pesquisa, salvaguarda (conservação e documentação) e comunicação (exposição e educação). 0 ciclo se fecha, sem nunca se completar, com a comunicação, sendo que esta não é a última etapa do processo, ou seja, na sinergia a comunicação atua igualmente e simultaneamente e não como etapa posterior que se desdobra das outras.

Comunicação museológica - na contramão dos ideais que a hegemonia faz questão de manter - não consiste na absorção pelo público de um conhecimento transmitido a ele pelo museu, como um indivíduo submisso ao impacto da mensagem museológica, ora passivo, ora reativo. Entretanto, a comunicação museológica não se encerra no museu - o meio - e sim no cotidiano das pessoas. A moderna teoria da comunicação fez deslocar as discussões dos "meios para as mediações" culturais que ocorrem no cotidiano das pessoas (Martín-Barbero 1997). Com isto, entende-se que o cotidiano do público é o mediador da sua participação interpretativa, ou seja, o público em museus interpreta a partir da sua experiência vivencial. Indo além, entende-se que o público é participante do processo museológico porque ele traz para o museu a sua interpretação. Interpretar, para os esclarecimentos devidos, é uma ação associada de forma indissociável à "leitura" e a "(re)significação": não há leitura sem interpretação, do contrário não houve leitura de fato, pois ninguém lê exatamente igual ao outro. Ler não é simples decodificação de "palavras". Por outro lado, não há interpretação sem leitura (que é o que permite a interpretação) e a interpretação é, em si, recriação de significados, ou ressignificação. Neste sentido, a comunicação museológica é comunicação dos sentidos patrimoniais e as mensagens implícitas e explicitas em uma exposição são proposições de significados que serão (des)construídos, reelaborados, negociados, trocados, pelo visitante em atitude dialógica com o museu. 
0 projeto de comunicação do Museu Água Vermelha - que engloba a exposição e a ação educação vinculada a ela - partiu destes pressupostos.

Inicialmente, e entendendo que a recepção é um processo que antecede e sucede a visita a um museu e a uma exposição, foi realizado um estudo com um dos públicos prioritários do museu: estudantes dos ensinos fundamental e médio. ${ }^{16}$

Para a museologia, esta é uma das formas de avaliação museológica, ${ }^{17}$ que se enquadra nos chamados estudos de público, 0 que denominaremos de pesquisa de recepção. Assim, dentro da perspectiva da pesquisa de recepção, foi desenvolvida uma avaliação conceitual, preliminarmente à elaboração da exposição, com estudantes.

Partimos da constatação que a comunicação institucionalizada da arqueologia está na mão da escola e do museu. Sabemos, no entanto, que há um descompasso entre a (pouca) quantidade de museus arqueológicos e a amplitude e complexidade dos conhecimentos sobre arqueologia brasileira. Sabemos, também, que, na escola o professor, sem suportes outros, apóia-se no livro didático como instrumento para ministrar os conteúdos arqueológicos. Recente estudo analisou "A abordagem do período pré-colonial brasileiro nos livros didáticos do ensino fundamental" (Vasconcellos et al. 2000) e nos apontou algumas vertentes a partir de um conjunto de 12 livros de 10 autores, selecionados ou por critérios mercadológicos (os mais vendidos) ou pelo oficial (aqueles indicados para a escolha pelos professores $\mathrm{da}$ Rede Pública de Ensino para posterior distribuição gratuita aos alunos). Os autores, na análise que fizeram, apresentaram diversas

(16) A pesquisa de recepção desenvolvida no Museu Água Vermelha compreendeu duas etapas: a preliminar à exposição e a pós montagem. Este texto apresenta a etapa preliminar e como esta se vinculou à concepção da exposição.

(17) Quanto às formas de comunicação museológica, vide Cury 2006. questões: a postura evolucionista de alguns, periodização européia como referência em outros, e - quando há um enfoque brasileiro o texto é de autoria de historiador desvinculado da produção em arqueologia. Os autores concluíram o estudo com a triste constatação de que é do professor a incumbência de desconstruir e reconstruir com seus alunos o conhecimento sobre esse passado, recorrendo, para tanto, ao museu de arqueologia como espaço de produção e comunicação arqueológica (Vasconcellos et al. 2000: 237).

Voltamos ao ponto de partida: são poucos os museus; o professor recorre ao livro didático, cuja mensagem precisa ser (des)construída por ele com base nas informações comunicadas pelos museus de arqueologia!

Em síntese, não sabemos o que os brasileiros pensam sobre arqueologia. O que sabemos (ou temos como hipóteses) é que os brasileiros recebem informações superficiais e desconexas ou descontextualizadas; às vezes preconceituosas, importadas e, outras vezes, fantasiosas.

Em Ouroeste, os estudantes que participaram da pesquisa conviveram nas ruas com arqueólogos, receberam alguma informação sobre o que estava acontecendo e estavam bastante curiosos com o "cemitério de índio" em um dos sítios arqueológicos junto à Usina Água Vermelha.

\section{Pesquisa de recepção: a avaliação conceitual}

A pesquisa foi realizada em março de 2003, e antes de iniciar a concepção da exposição Ouroeste: 9 Mil Anos de História, por meio da aplicação de um questionário em estudantes da $7^{a}$ e $8^{a}$ séries do ensino fundamental e de $1^{\circ}, 2^{\circ}$ e $3^{\circ}$ anos do ensino médio da E. E. Sansara Singh Filho. O objetivo foi aferir o conhecimento que esses estudantes tinham sobre arqueologia e sobre o passado pré-colonial brasileiro. 298 estudantes participaram dessa etapa da pesquisa de recepção. 
Considerando que esta etapa da pesquisa tem interesse central na relação dos estudantes com a questão indígena, e nos conhecimentos que eles possuem sobre arqueologia, organizamos as perguntas do questionário para averiguação dessas questões. No entanto, não fizemos distinção entre etnologia e arqueologia e índio dos períodos pré-colonial e contemporâneo, até porque não há a presença indígena na região atualmente ou num passado próximo. A presença indígena existe nos nomes de algumas cidades, na referência do rio Grande e no imaginário sobre a cachoeira dos Índios (destruída para a construção da usina). Essa "mistura" de entendimento por parte do público e os discursos que ela gera são construções, enunciações elaboradas e assimiladas. Não pretendemos levantar e analisar esses discursos - adentrar em suas camadas e buscar suas raízes e estrutura de funcionamento -, o que seria muito frutífero para a comunicação da arqueologia, mas seria um estudo de profundidade - e de extrema necessidade - que a pesquisa em questão não comportou.

Por outro lado, não consideramos, na pesquisa, que a arqueologia seja um campo vasto que envolve a construção de conhecimento por meio de vestígios da cultura material, do passado pré-colonial ou colonial, e mesmo do presente. Consideramos, sem entrar no mérito com os estudantes, a arqueologia pré-histórica.

O questionário contou com questões com múltiplas escolhas, com espaços para justificativas ou esclarecimentos por meio de respostas abertas.

Os dados sofreram uma análise quantitativa e tornaram-se fundamentais para a concepção da exposição.

\section{A primeira fala dos receptores}

Esta etapa do estudo revelou aspectos importantes sobre a população jovem da cidade. Ouroeste é uma cidade jovem, pois tem apenas 52 anos de existência e $8^{18}$ de emancipação de Guarani D’Oeste, da qual era distrito. De acordo com o censo de 2002, 0 município possui 6290 habitantes - sendo 3159 homens e 3131 mulheres - e 5387 eleitores (87\% da população). Em 2004 ocorreram 1073 matrículas no ensino fundamental e 419 no ensino médio. 0 município possui três escolas de ensino fundamental, duas de ensino médio e duas de educação infantil. Destas apenas uma é particular.

Os dados coletados com os estudantes revelaram que apenas $13(4,4 \%)$ nasceram em Ouroeste e nenhum em cidades limítrofes (Fernandópolis, Indiaporã, Guarani D'Oeste e Paranapuã). 10,1\% deles nasceram na região (aproximadamente $150 \mathrm{~km}$ ao redor de Ouroeste), ou seja, apenas estes dois percentuais (na soma, 14,5\%) têm vínculos com a história regional e com a memória do território, e os demais $(81,1 \%)$ precisam construir vínculos territoriais. $24,8 \%$ dos estudantes vivem há até 5 anos na cidade, $14,4 \%$ vivem entre 6 e 10 e 49,3\% vivem 11 anos ou mais.

Desses 298 estudantes, 144 (48,3\%) são do ensino fundamental e $154(51,7 \%)$ do ensino médio.

A idade desses estudantes varia entre 12 e 18 anos. No ensino fundamental temos um grande número de adolescentes entre 13 $(47,9 \%)$ e 14 anos $(25,7 \%)$. No ensino médio temos uma concentração maior entre 15 $(40,9 \%)$ e 16 anos (37\%). Os dados de idade não surpreendem, principalmente porque são estudantes dos períodos da manhã e da tarde.

\section{A relação dos estudantes com a arqueologia}

Diversas questões foram feitas para levantar o nível de conhecimento dos estudantes sobre arqueologia. Uma delas foi se eles já estudaram, e quando, a pré-história bra-

(18) Dados referentes ao ano de 2005, quando a pesquisa, quando a pesquisa foi concluída. 
sileira. Dos que responderam $\operatorname{sim}(32,9 \%)$, a maioria aprendeu na escola em várias séries entre a $4^{a}$. do ensino fundamental e 0 $3^{\circ}$. ano do ensino médio, e alguns $(1,3 \%)$ aprenderam pela TV ou com o pai. $6,4 \%$ deles não se lembram em que séries aprenderam. $18,1 \%$ dos estudantes responderam que não estudaram, 47,3\% não se lembram e $1,7 \%$ não respondeu à questão. Nesta questão usamos o termo pré-história por ser o mais familiar nos livros didáticos.

Procuramos, então, levantar o que eles sabem sobre pré-história por meio de uma questão direta. Pedimos a eles respostas diretas também, deixando-os à vontade para ser sinceros, pois não estavam sendo testados. As respostas foram diretas: $52,3 \%$ dos 298 estudantes responderam "não sei nada" ou "não me lembro de nada", sendo que $63,9 \%$ dos 144 alunos do ensino médio tiveram esta resposta, bem como $41,6 \%$ dos 154 dos alunos do ensino fundamental. Apenas $19,1 \%$ relacionaram a pré-história à existência de índios no passado $(13,8 \%)$, a homens que viviam em cavernas $(1,3 \%)$, ou com um modo de vida diferente do nosso, precisando fazer fogo $(1 \%)$, e que a pré-história foi antes da nossa colonização ou na Grécia (3\%). Alguns consideram que sabem pouco $(13,4 \%)$, e outros $(2,3 \%)$ afirmaram que sabem muito ou tudo. Nos dois casos os respondentes não discriminam o "pouco" ou o "muito" que conhecem. 9,1\% deles não responderam. As respostas relacionando pré-história a dinossauros não foram muitas, como se poderia supor: apenas $6,4 \%$ da amostra.

Quanto à questão: "O que é arqueologia para você?", uma parcela grande da amostra $(34,6 \%)$ não sabe e $6 \%$ dela não respondeu. Para os demais, (1) a arqueologia estuda civilizações, ou povos antigos, ou seres pré-históricos, ou os índios brasileiros $(23,1 \%)$; (2) a arqueologia estuda coisas, objetos antigos/do passado, estuda ossos $(19,4 \%)$; (3) a arqueologia estuda ossos de animais, como os dinossauros ou fósseis $(9,1 \%)$; (4) a arqueologia faz descobrimentos em vários países e é um trabalho bonito, uma coisa incrível $(7,8 \%)$.
E "Você acha arqueologia importante?" $64,8 \%$ acham que sim, 25,2\% não sabem, $7,7 \%$ acham que tem uma importância relativa e $2 \%$ não acham a arqueologia importante. Dos comentários que fizeram, para $27,8 \%$ da amostra de 298 que responderam sim, da justificativa é que: a arqueologia é importante para que possamos descobrir/ saber como viviam os antepassados $(24,8 \%)$, ou para desvendar a nossa evolução e as origens da humanidade (3\%). 7,4\% acham a arqueologia importante porque ela descobre coisas antigas. Para $13,1 \%$ da amostra, a arqueologia é uma forma de aprender fatos novos e diferentes, e para $4,7 \%$, toda profissão é importante. Apenas $2 \%$ dos respondentes acham a arqueologia importante para se saber mais sobre a história da região e do País. Apesar de considerarem a arqueologia importante, $9,7 \%$ dos estudantes não se justificaram. Aqueles que relativizaram a importância da arqueologia ou não a consideram importante, não manifestaram interesse especial, acham-na chata ou desconhecem o suficiente para manifestar opinião.

Com relação ao interesse dos estudantes com a disciplina arqueologia, $61,4 \%$ se consideram interessados, $31,5 \%$ não se consideram, $5,7 \%$ não sabem e $1,4 \%$, mais ou menos ou não respondeu.

Indagados sobre os motivos do interesse pela arqueologia, um terço aproximadamente da amostra manifestou ser uma pessoa curiosa por descobertas arqueológicas $(5,4 \%)$, gostar de ampliar seus conhecimentos $(16,8 \%)$, sobretudo com estudos interessantes e importantes (12,8\%). Muitos vêem na arqueologia uma possibilidade para saber sobre povos antigos $(17,1 \%)$ e sobre os antepassados (5,7\%). 2,7\% da amostragem acha a arqueologia legal e quer ser arqueólogo(a). 3,7\% acham a arqueologia interessante, mas não justificaram por quê.

Os motivos pelo desinteresse ou pouco interesse pela arqueologia, diríamos, está relacionado à desinformação. Podemos supor que eles (31,5\% da amostra) não têm interesse porque não conhecem ou não sa- 
bem do que se trata $(12,4 \%)$, não têm vontade $(6,4 \%)$, não gostam de procurar ossos ou coisas antigas ( $1 \%)$, não gostam de terra $(0,3 \%)$, não sabem o porquê do desinteresse $(3 \%)$, ou não responderam $(8,1 \%)$. Aqueles que têm um interesse relativo $(0,6 \%)$ relacionam o não-interesse à falta de oportunidade ou à forma sem atratividade como a arqueologia é apresentada.

Como já mencionamos, em 1997 houve a descoberta do sítio-cemitério, e entre 1997 e 1998, e depois em 2002 foram realizadas escavações arqueológicas. Isso teve alguma repercussão na cidade, pois a presença das equipes de arqueologia foi notada e comentada. Além disso, a descoberta do cemitério indígena foi amplamente noticiada e os arqueólogos fizeram um trabalho de extensão universitária com a escola estadual entre 1997 e $1998 .{ }^{19}$ Com base nisso, procuramos averiguar se os estudantes correlacionavam esses fatos a uma descoberta arqueológica. A pergunta feita foi: "Recentemente você soube de alguma descoberta arqueológica?"

$74,5 \%$ da amostra respondeu não, 22,8\% respondeu sim, e 2,7\% não respondeu. Dos que responderam $\operatorname{sim}$, apenas $12,4 \%$, considerando a amostra total, relacionaram os ossos dos índios e a machadinha achados na represa (Usina Água Vermelha) com uma descoberta arqueológica. $4,7 \%$ se lembraram de descobertas em caverna no Ceará ou de outras no Oriente Médio, e 2,7\% se lembraram de descobertas paleontológicas de dinossauros. $1 \%$ não se lembra e $2,7 \%$ não responderam.

Dando continuidade ao levantamento do que sabiam sobre a disciplina, perguntamos se para eles a arqueologia brasileira era tão avançada quanto em outros lugares. $54,3 \%$ da amostra não soube responder, $18,8 \%$ acha que é relativamente avançada com relação a outras localidades, $18,1 \%$ acha que não, e 8,7\% acha que sim.

(19) Tendo ocorrido há 5 ou 6 anos, os estudantes da pesquisa não foram, muito provavelmente, espectadores desse trabalho de extensão arqueológica.
Quanto aos comentários daqueles que acham que é relativamente avançada, 8,7\% da amostra não comentou, 4,7\% relacionoua com a situação econômica do Brasil, e/ou à falta de recursos ou apoio governamental, $3,7 \%$ acha que há desinteresse interno e que as maiores descobertas são em outros países, $1,7 \%$ acha que a arqueologia no Brasil está avançando da mesma forma que em outros países.

Daqueles que responderam que a arqueologia brasileira não é tão avançada quanto outras, $5,4 \%$ da amostra não justificou a sua opinião. Vários estudantes procuraram justificativas externas ao Brasil: a tecnologia externa é mais avançada $(5,4 \%)$, a maioria das descobertas é de fora $(1,7 \%)$, os outros têm mais condições financeiras $(0,7 \%)$, os arqueólogos internacionais são mais competentes $(0,7 \%), 5,4 \%$ procuraram justificativas internas: a arqueologia no Brasil está se iniciando agora $(1,7 \%)$, mal se houve falar nela e poucos a conhecem $(1,7 \%)$, falta interesse em geral $(1,3 \%)$, e incentivo do governo $(0,7 \%)$.

Dos que responderam sim, 3,4\% não justificaram, 2,3\% acham que aqui já ocorreram descobertas e ainda há muito material a ser encontrado, 1,7\% equipara o desenvolvimento da arqueologia no Brasil a outras profissões, 1,4\% entende que a arqueologia é uma coisa só no mundo e que o Brasil tem capacidade de descobrir.

$56 \%$ da amostra não teria interesse em fazer algum tipo de pergunta a um arqueólogo, 19,5\% gostaria de fazer alguma pergunta, mas não soube elabora-la no momento do preenchimento do questionário. As perguntas que gostariam de fazer foram categorizadas. A primeira categoria versa sobre a arqueologia e tivemos $8,6 \%$ de dúvidas. As perguntas eram sobre: 0 que a arqueologia estuda? Como e quando surgiu a arqueologia? Há quanto tempo há arqueologia no Brasil? Como se descobre alguma coisa? Como se sabe a idade de alguma coisa? Como se descobre como eram os seres a partir dos restos mortais? Na segunda categoria temos perguntas mais relacionadas à 
profissão ou ao desempenho do arqueólogo $(4,6 \%)$ como: Por que você se interessa por arqueologia? Como eu poderia me tornar um arqueólogo? Posso participar de uma escavação com você? O que você mais gosta de pesquisar? É difícil exercer essa profissão? Numa terceira categoria temos curiosidades $(4,1 \%)$ como: Qual a sua descoberta mais interessante? Qual foi o objeto mais antigo que você descobriu? Você já achou algum osso estranho de alguma coisa desconhecida? Perguntaria sobre o peixe na caverna, se existiu múmia no Brasil e quando e quantas ossadas já descobriu, qual foi a surpresa quando soube do cemitério [junto à Usina Água Vermelha]. Na quarta categoria as questões são sobre as culturas descobertas pela arqueologia (2,3\%): Há quantos anos os índios vivem no Brasil? Gostaria de saber mais sobre os povos de antigamente? Quais foram os primeiros povos que habitaram a região? Como era a vida dos índios? A quinta categoria agrupa questões sobre dinossauros e sobre fósseis $(3,4 \%)$ : Já foram encontrados outras espécies sem ser de dinossauros? Já achou algum dinossauro? Você assiste ao "Mundo do dinossauro"? Na região teve alguma espécie de dinossauro? Como descobriram os ossos de dinossauros? Qual foi o primeiro fóssil descoberto? Uma pessoa queria saber qual seria o nome do museu.

De outras experiências de atendimento a público escolar, sabemos que é (ou era) comum os estudantes relacionarem o profissional arqueólogo ao personagem fictício do cinema Indiana J ones. Também correlacionam a arqueologia à busca de tesouros, contribuição negativa do cinema à ciência e à legislação e preservação patrimoniais. Assim, elaboramos algumas perguntas para constatação disso. Indagados se eram verdadeiras ou falsas as afirmações de que:

- "Os arqueólogos procuram tesouros de outros povos" $59,7 \%$ a consideraram falsa, $33,9 \%$ verdadeira, e $6,4 \%$ não responderam;

- "Os arqueólogos procuram conhecer 0 modo de vida de povos antigos por meio de objetos deixados por eles e que foram soterrados", 90,6\% consideraram a afirmativa verdadeira, $4,7 \%$ a consideraram falsa, e $4,7 \%$ não responderaram;

- para a afirmação de que "os arqueólogos são grandes aventureiros", 77,9\% acharam que sim, 15,4\% acharam que não, e $6,7 \%$ não responderam.

- para 44\% da amostra, "um dos arqueólogos mais conhecidos é Indiana Jones", para $42,3 \%$ ele não é um dos mais conhecidos, e $13,8 \%$ não responderam.

Por outro lado, muitas pessoas levadas pela falta de conhecimento sobre o passado pré-colonial do Brasil compararam o nosso passado ao de outros locais depreciando 0 índio brasileiro. Assim, declararam que:

- "No Brasil não viveram civilizações importantes como maia, asteca e inca", para $56,4 \%$ essas idéias eram falsas; para $36,6 \%$, eram verdadeiras, e $7 \%$ não responderam.

Todas essas questões de "verdade ou mentira", "acredito ou não acredito", "concordo ou não concordo", nos dão uma primeira informação que mereceria ser aprofundada. Ao indagar sobre esses pontos, apenas tiramos uma primeira camada de muitas outras que constituem o modelo que 0 brasileiro tem sobre o passado précolonial, e em certa medida, sobre o próprio brasileiro.

\section{A relação dos estudantes com o índio brasileiro}

Essa abordagem - o índio brasileiro - é muito ampla e complexa e não tivemos a intenção nesta pesquisa de conhecê-la a fundo, ou de esgotá-la. Interessou-nos, no entanto, sentir um pouco do que os estudantes pensam e sabem para levantar pontos de aproximação e/ou de distanciamento, considerando que a história da região cruza com as ocupações indígenas pré-coloniais.

Como já afirmado anteriormente, não levamos em consideração a distinção entre arqueologia e etnologia porque o público também não a faz. 
Para começar, foi feita a afirmação: "Antes da chegada de Pedro Álvares Cabral em 1500, o Brasil já era todo ocupado por índios", e pedimos aos adolescentes que dissessem se para eles era verdadeira ou falsa. Para $51,7 \%$ a afirmação é verdadeira, para $32,2 \%$ é relativa, e para $12,4 \%$ é falsa.

Solicitei que comentassem a resposta. Dos que consideram a afirmativa verdadeira, $31,9 \%$ não comentaram e os outros $(19,8 \%)$ consideram que os índios eram os primeiros habitantes e donos do Brasil, que havia muitos deles, que travavam guerras entre si e foram assassinados ou foram sumindo após o descobrimento. Os estudantes têm provas disso: o cemitério junto à usina é uma evidência; a história e os professores comprovam também.

Dos que acham que é uma verdade relativa, $17,8 \%$ não comentaram e $14,4 \%$ acham que só uma parte do Brasil era ocupada ou quase todo e não tudo, só no litoral, as matas e florestas.

Dos que acharam a afirmativa falsa, $6 \%$ não comentaram e $6,4 \%$ acham que é falsa porque só uma parte era ocupada e não havia só índios aqui.

Outra afirmativa, agora para eles dizerem se acreditam ou não: "Viviam no Brasil mais de 5 milhões de índios na época do descobrimento." Da amostra, 37,9 \% acreditam, $44 \%$ dizem que acreditam mais ou menos, $13,1 \%$ não acreditam e $5 \%$ não responderam. Vejamos o que eles comentaram.

Para aqueles de respostas afirmativas, $21 \%$ não comentaram a sua concordância, e para os outros $16,9 \%$, havia muitos índios em todo o extenso território, eles se reproduziam e as gerações aumentavam, os livros falam sobre isso.

Para aqueles que concordam com ressalvas, $32,9 \%$ não comentaram. Os comentários que temos $(11,1 \%)$ são que não sabem 0 número exato e pode ser isso, mas deve ser um pouco menos, pois o território é grande.

Daqueles que não concordam, 10,4\% não comentaram e os demais $2,7 \%$ acham o número muito grande e nunca ouviram falar na quantidade.
Quando indagados sobre: "O que você sabe sobre os índios que moraram na região de Ouroeste?" 80,9\% responderam que não sabem ou não se lembram de nada. Quanto aos demais da amostra, $8,4 \%$ disseram que a região foi habitada por índios há muitos anos; para 2,3\% eles moravam na cachoeira dos Índios; na opinião de 1,7\%, eram índios comuns que caçavam e pescavam, eram trabalhadores; e no entender de 0,3\%, os índios moravam em cabanas ou em $(0,3 \%)$ casas simples de pau-a-pique e palha, em grandes aldeias; para 0,3\%, dominavam 0 fogo; para $0,3 \%$, faziam sepultamentos. Eram os tupi-guaranis $(0,7 \%)$. Alguns estudantes conhecem evidências de índios na região, como os ossos achados recentemente $(3,4 \%)$, o avô que falava que eles escreviam em pedras $(0,3)$, e porque algumas cidades têm nomes indígenas ( $1,3 \%$ ). Um aluno acha que eles foram embora quando explodiram a cachoeira dos Índios, um outro viu um índio e ele parecia ser bom e um terceiro acha que o fato da região ter sido habitada por índios é bom, para a história da cidade.

Perguntamos, então, o que eles gostariam de saber sobre os índios que moraram na região. 4,3\% não sabiam o que perguntar ou não responderam; $9,1 \%$ não gostariam de saber nada; $1,3 \%$ quer saber só 0 necessário; 39,6\% querem saber tudo, 0 máximo possível; 34,9\% dos estudantes querem saber sobre o modo de vida, hábitos e sobre a cultura em geral; $6,4 \%$ sobre comida e obtenção de alimentos; 3,4\% querem saber sobre a origem dos índios, como e por onde vieram para a região; $3 \%$, a época em que chegaram; $1 \%$, como era a região na época; $2,3 \%$, onde viviam; $2 \%$, qual era 0 nome da tribo; $2 \%$, como era a convivência entre eles; $1,7 \%$, qual era a religião deles e se acreditavam em vários deuses ou em um só; $1,3 \%$, como se vestiam e se se vestiam; $1 \%$, como eram as casas; $1 \%$, quantos índios eram; $0,7 \%$, porque enterravam os mortos naquele lugar; $0,3 \%$, se eram alegres; $0,3 \%$, se viviam bem; $0,3 \%$, como faziam remédios; $0,3 \%$, como se pintavam; $0,3 \%$, como eram as armas de guerra; $0,7 \%$, por 
que eles foram embora; $0,7 \%$ gostaria de vê-los, e 0,3\% gostaria de saber se há a possibilidade de os índios se juntarem a eles; 0,3\% gostaria de ver peças dos índios no museu.

Apoiados em um comentário corriqueiro de que "o índio brasileiro é preguiçoso", solicitamos aos estudantes que dissessem se essa idéia era falsa ou verdadeira, mesmo nos arriscando a reforçar uma idéia negativa sobre o índio. Bem, $83,9 \%$ acharam que a afirmação é falsa; $12,1 \%$, verdadeira, e $4 \%$ não responderam.

Gostaríamos também de verificar o conhecimento dos estudantes quanto à diversidade cultural entre os índios brasileiros. Pedimos para comentarem se falsa ou verdadeira a afirmativa de que "os índios eram todos iguais". Para $71,1 \%$ da amostra, era falsa; para $25,2 \%$, era verdadeira, e $3,7 \%$ deles não responderam.

A última questão que queremos comentar é: "O que você sabe sobre o cemitério encontrado perto da represa?" Quase dois terços dos alunos $(63,8 \%)$ responderam que não sabem nada ou não se lembram. As respostas não elucidam muita coisa. $20,8 \%$ disseram que era um cemitério de índios; $7 \%$ sabem onde fica e já foram lá; $3 \%$ sabem que junto aos ossos foram achados objetos e uma machadinha, $2,7 \%$ sabem quem são os pescadores que encontraram o cemitério; $1,7 \%$ sabe que eles acharam muitos ossos e fósseis de índios; para 0,7\%, o fato ocorreu após a "caída" de uma árvore; para $1 \%$, o local está fechado para estudo; para $0,7 \%$, encontra-se com um portão com cadeado; para $1,7 \%$ o local é sagrado, patrimônio da humanidade e, assim, resolveram fazer um museu para guardar o que foi achado.

\section{A exposição e a ação educativa Ouroeste: 9 Mil Anos de História}

A exposição e a ação educativa são manifestações da política de um museu e, para o público, é o que define a instituição. Há uma verdade nisto, pois são os usos que o público faz dos museus que lhes dão forma social.

Neste sentido, e a partir da pesquisa conceitual realizada com os estudantes, uma equipe interdisciplinar ${ }^{20}$ conceituou a exposição de longa duração do Museu Água Vermelha, Ouroeste: 9 Mil Anos de História. Coube a essa equipe a construção do método e estratégias de trabalho e, sobretudo, a estruturação da linguagem expositiva.

Quanto à linguagem, inicialmente buscamos a interação entre "saberes" - arqueológico, museológico e do público. A preocupação foi criar uma exposição inteligível, com fundamentação arqueológica e sustentação museológico-comunicacional. Sendo assim, os conteúdos inerentes a estes saberes, dialogando entre si de forma interdiscursiva, propiciaram a construção de um mapa cognitivo, conforme tabela 1. Para que fique clara a nossa opção, a lógica da exposição respeitou os campos envolvidos, tendo como referencial o público interprete, o que não significa que a arqueologia - a área a ser comunicada - não tenha sido respeitada e valorizada, da mesma forma que os arqueólogos ${ }^{21}$

(20) Ficha técnica da exposição Ouroeste - 9 Mil Anos de História: Projeto Museológico e Coordenação: Marília Xavier Cury. Projeto Expográfico: Marília Xavier Cury, Mauro de Vasconcelos Coelho, Ana Carla Alonso, Aureli Alves de Alcântara, Joana Montero Ortiz. Coordenação Científica: Erika Robrahn-González, Paulo A. D. De Blasis. Consultoria Científica: Levy S. Figuti, Sabine Eggers. Apoio Administrativo: Emília Paula Vieira. Programação Visual: Cristiane Y. Sato, Raquel M. Yoshizawa, Mariana A. Iwanaga. Adereçagem: Gil Verx. Cerâmica: Shoichi Yamada. Fotografia: Erika Robrahn-González, José Roberto Pellini, Wagner Souza e Silva. Ilustração: Chico Bela. Maquetes: Kenji Maquetes. Apoio Técnico: Cintia Bendazolli Simões, Daria Elânia Fernandes Barreto, José Paulo Jacob, Fernando Victor Aguiar Ribeiro, Juliana de Souza Batista. Agradecimento: Adelino Francisco do Nascimento, Osterno Machado, Danilo Chagas Assunção, Daniela Magri Amaral, Gerson Levy da Silva Mendes, Manoel Mateus Bueno Gonzalez, Paulo Zanettini, Silvana Viana Cruz de Macedo. Projeto Executivo, Produção e Montagem: Cinestand Serralheria e Cia.

(21) Quanto à metodologia adotada e à participação dos arqueólogos e demais membros da equipe, vide Cury 2005. 


\section{Tabela 1}

Mapa Cognitivo da exposição e ação educativa

\begin{tabular}{|c|c|c|}
\hline $\begin{array}{l}\text { Discurso } \\
\text { Arqueológico }\end{array}$ & $\begin{array}{l}\text { Discurso } \\
\text { Expositivo }\end{array}$ & $\begin{array}{l}\text { Discurso } \\
\text { Educativo }\end{array}$ \\
\hline $\begin{array}{l}\text { Conhecimento metodológico, } \\
\text { científico e técnico. } \\
\text { Conhecimento das especiali- } \\
\text { dades dentro da arqueologia. } \\
\text { Conhecer as áreas auxiliares } \\
\text { à arqueologia }\end{array}$ & $\begin{array}{l}\text { Quadras, trincheiras, } \\
\text { estratigrafia, vestígios, } \\
\text { registro, técnicas, equipa- } \\
\text { mentos e materiais. } \\
\text { Organização do laboratório. } \\
\text { Registro de dados. } \\
\text { Análise e interpretação }\end{array}$ & $\begin{array}{l}\text { Raciocínio lógico e abstrato. } \\
\text { Inferência.Presente }\end{array}$ \\
\hline $\begin{array}{l}\text { Origem e expansão dos } \\
\text { grupos que se assentaram } \\
\text { na região. } \\
\text { Períodos de ocupação. } \\
\text { Formas de ocupação. } \\
\text { Reconhecimento das tradi- } \\
\text { ções arqueológicas. } \\
\text { Tecnologia. } \\
\text { Intercâmbio entre grupos. } \\
\text { Sistema arqueológico } \\
\text { regional. } \\
\text { Modelos de expansão. }\end{array}$ & $\begin{array}{l}\text { Ocupação } \\
\text { Origem } \\
\text { Datação } \\
\text { Densidade demográfica } \\
\text { Diversidade } \\
\text { Obtenção de alimento } \\
\text { Território } \\
\text { Aldeia } \\
\text { Organização } \\
\text { social } \\
\text { Sepultamento } \\
\text { Cemitério } \\
\text { Ritual } \\
\text { Tecnologia } \\
\text { Passado }\end{array}$ & $\begin{array}{l}\text { Antiguidade } \\
\text { Antepassado } \\
\text { Dieta alimentar como cultura } \\
\text { Gosto alimentar } \\
\text { Memória territorial } \\
\text { História territorial } \\
\text { Vida } \\
\text { Estilo de vida } \\
\text { Instrumentos } \\
\text { Utensílios } \\
\text { Casa e lar } \\
\text { Família } \\
\text { Morte e perda } \\
\text { Ente querido } \\
\text { Cerimônia } \\
\text { Religião } \\
\text { "Medicina tropical" } \\
\text { Igualitarismo } \\
\text { Solidariedade } \\
\text { Cooperação } \\
\text { Tolerância } \\
\text { Exxito cultural } \\
\text { Tradição } \\
\text { Continuidade } \\
\text { Presente }\end{array}$ \\
\hline
\end{tabular}

Assumindo este compromisso conosco e com o público, fugimos dos modelos "estetizantes" de exposição, aqueles que não querendo recair num didatismo à semelhança do livro escolar, limitam-se a apresentar objetos com poucas informações - basicamente em etiquetas e textos - em situações técnicas (iluminação, vitrinas, etc.) favoráveis ao objeto. Esta é uma forma de fetichizar os objetos museológicos e distanciar o público deles.

Entendemos que 0 enfrentamento da linguagem expositiva seria o caminho para transpor 0 falso dilema didatismo $X$ valorização do objeto. Assim, a partir do mapa cognitivo definimos os objetivos da experiência do público (tabela 2), considerando que esta se daria com a sobreposição entre exposição e ação educativa. 


\section{Tabela 2}

Objetivos

\begin{tabular}{|c|c|}
\hline Exposição & Ação educativa \\
\hline $\begin{array}{l}\text { Fazer conhecer a pesquisa arqueológica e as } \\
\text { áreas científicas parceiras. } \\
\text { Apresentar a lógica do espaço. } \\
\text { Conhecer o método. } \\
\text { Estabelecer relação entre espaço horizontal } \\
\text { e vertical, espaço de ocupação e antiguidade. } \\
\text { Conhecer a lógica de um laboratório. } \\
\text { Entender as formas de análise de vestígios. } \\
\text { Distinguir entre material lítico, cerâmico, } \\
\text { faunístico e humano. } \\
\text { Conhecer a lógica da análise e interpretação. } \\
\text { Conhecer o método de datação Carbono } 14 \text {. }\end{array}$ & $\begin{array}{l}\text { Refletir sobre o espaço. } \\
\text { Ler estratigrafia. } \\
\text { Pensar arqueologicamente. } \\
\text { Imaginar.Criar hipóteses. }\end{array}$ \\
\hline $\begin{array}{l}\text { Conhecer os grupos que ocuparam a região. } \\
\text { Refletir sobre a diversidade cultural no pas- } \\
\text { sado pré-colonial da região. } \\
\text { Apresentar as formas de interação entre o } \\
\text { grupo e o território. } \\
\text { Conhecer as soluções sociais e culturais. }\end{array}$ & $\begin{array}{l}\text { Exercitar a tolerância. } \\
\text { Trabalhar para uma consciência de alteridade. } \\
\text { Discutir (re)tradicionalização. } \\
\text { Discutir (des)(re)territorialização. } \\
\text { Estabelecer vínculos entre culturas. } \\
\text { Refletir sobre a história do território. } \\
\text { Desenvolver uma memória territorial. } \\
\text { Desenvolver "gourmets" culturais - cidadãos } \\
\text { habilitados para criar pontos de compreensão } \\
\text { entre culturas diferentes. }\end{array}$ \\
\hline
\end{tabular}

Partimos, então, para a construção do "jogo de equilíbrio" entre temática, objetos, espaço e tempo - os elementos estruturadores de uma exposição - e recursos de apoio. Construímos, então, uma ambiência expositiva (espaço significado) para oportunizar que o público pudesse interagir com a arqueologia e com 0 patrimônio arqueológico.

Em um espaço de $90 \mathrm{~m}^{2}$, com pé-direito duplo, estruturamos uma retórica narrativa em dois eixos principais:

- Histórico das descobertas arqueológicas

- Eixo 1- A construção do conhecimento na arqueologia

- A etapa de escavação

- A análise e interpretação em laboratório

- A exploração e prospecção regional

- O método Carbono 14 e a antigüidade do homem na região
- Eixo 2- As descobertas - As quatro ocupações no tempo

- Os primeiros povoadores de 9 mil anos atrás

- Os caçadores especializados de 5 mil anos atrás

- A era das grandes aldeias de 1500 anos atrás

- As sociedades complexas de 500 anos atrás.

- Encerramento: Arqueologia de Ouroeste

A narrativa foi organizada no espaço em forma de $\mathbf{U}$, pois a sala possui duas entradas. Apesar da estrutura narrativa, o público foi estimulado a explorar a exposição episodicamente, ou seja, ele mesmo fazer o seu circuito e, assim, a suas reelaborações. Para tanto, há uma ligação entre as pernas do $\mathbf{U}$ e a altura dupla da sala foi apropriada para a construção de possibilidades de apre- 
ciação por uma vista superior (por meio de um mezanino). De fato, são, ao menos, duas exposições com múltiplas possibilidades de recortes.

A definição dos dois eixos ocorreu para a argumentação e persuasão de que o conhecimento arqueológico construído em Ouroeste teve bases científicas, isto porque, como vimos, os estudantes (e provavelmente seus pais e irmãos) pouco sabem sobre arqueologia. Para não apresentar os resultados arqueológicos sem que os mesmos fossem fundamentados, apresentamos as armações de referência - a pesquisa em arqueologia como armações interpretativas. A própria exposição é um conjunto de armações interpretativas, fruto das intenções dos seus idealizadores, com as quais o público interage.

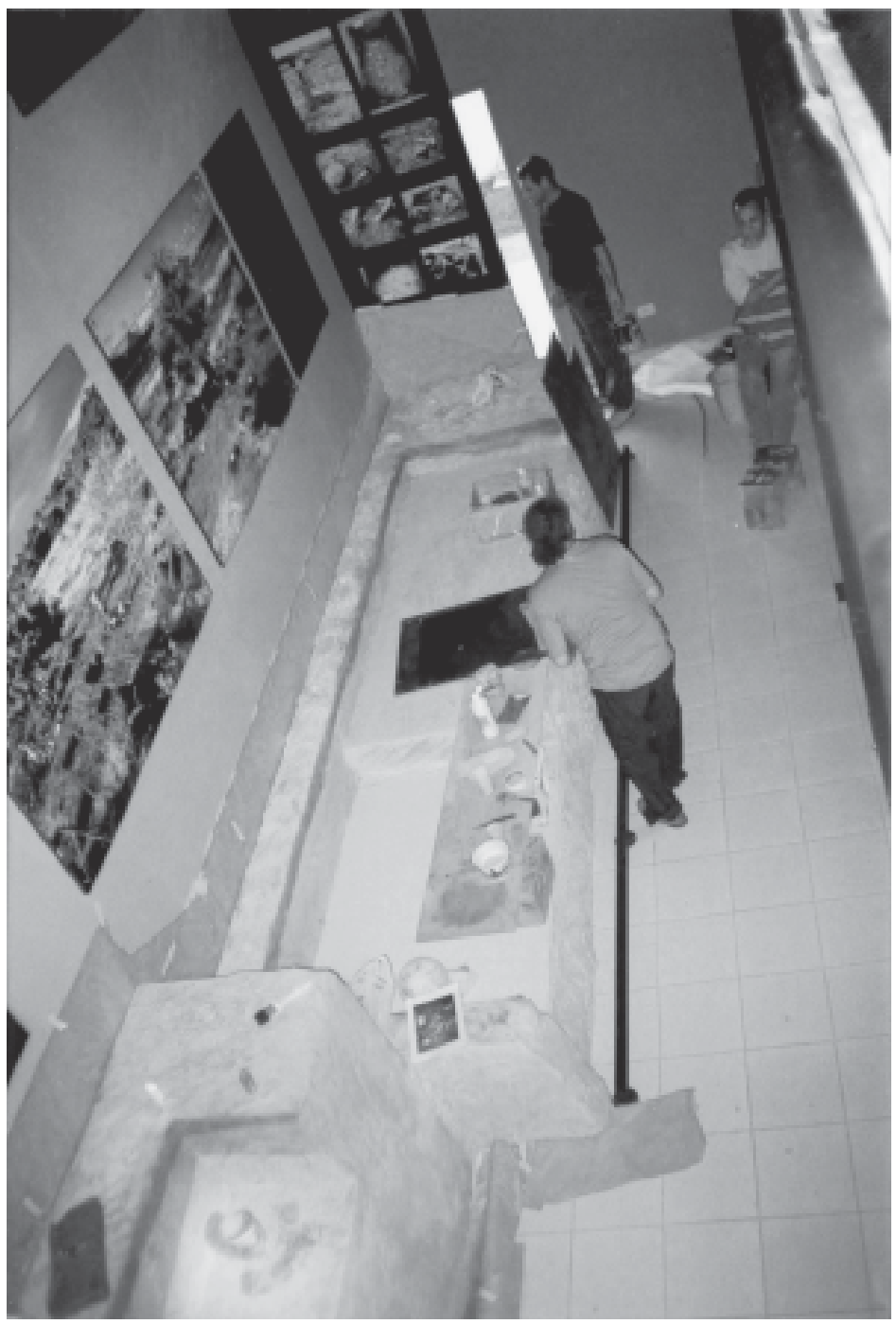

Foto 1 - Montagem da cenografia para A Etapa da Escavação 
Seguindo este princípio, e recorrendo sempre aos dados coletados com a avaliação conceitual, o Eixo 2 - "As descobertas", foi detalhado de forma padrão nos quatro submódulo: "Primeiros Povoadores", "Caçadores-Coletores Especializados", "A Era das Grandes Aldeias" e "Sociedades Complexas". A padronização foi: origem, datação, densidade demográfica, obtenção de alimento por caça, pesca, coleta e/ou agricultura; a preparação dos alimentos; o território de ocupação e de circulação; aldeia; organização do espaço; organização social, as formas de sepultamento, a tecnologia, uso dos artefatos.

Neste eixo, a narrativa foi estruturada a partir de questões do cotidiano dos grupos pré-coloniais em paralelo ao cotidiano do público-visitante. Assim, dentre as informa- ções arqueológicas destacaram-se aquelas que poderiam estabelecer formas de reconhecimento e de vínculos entre passado e presente, como: constituição da família e do grupo, alimentação, relação com o território, a casa na aldeia, a morte e os rituais de sepultamento, cooperação social - o que posteriormente demonstrou eficácia devido à forma como estes aspectos foram apropriados pelo público.

A ação educativa, o subtexto invisível porque atua essencialmente no plano subliminar, não foi pensada como reforço ou apoio à exposição (minimizando os problemas de linguagem da mesma). Ela vai além dela sem contradizê-la. Com a ação educativa conceitos como êxito cultural, alteridade e identidade, diferença e diversidade cultural, cooperação e organização

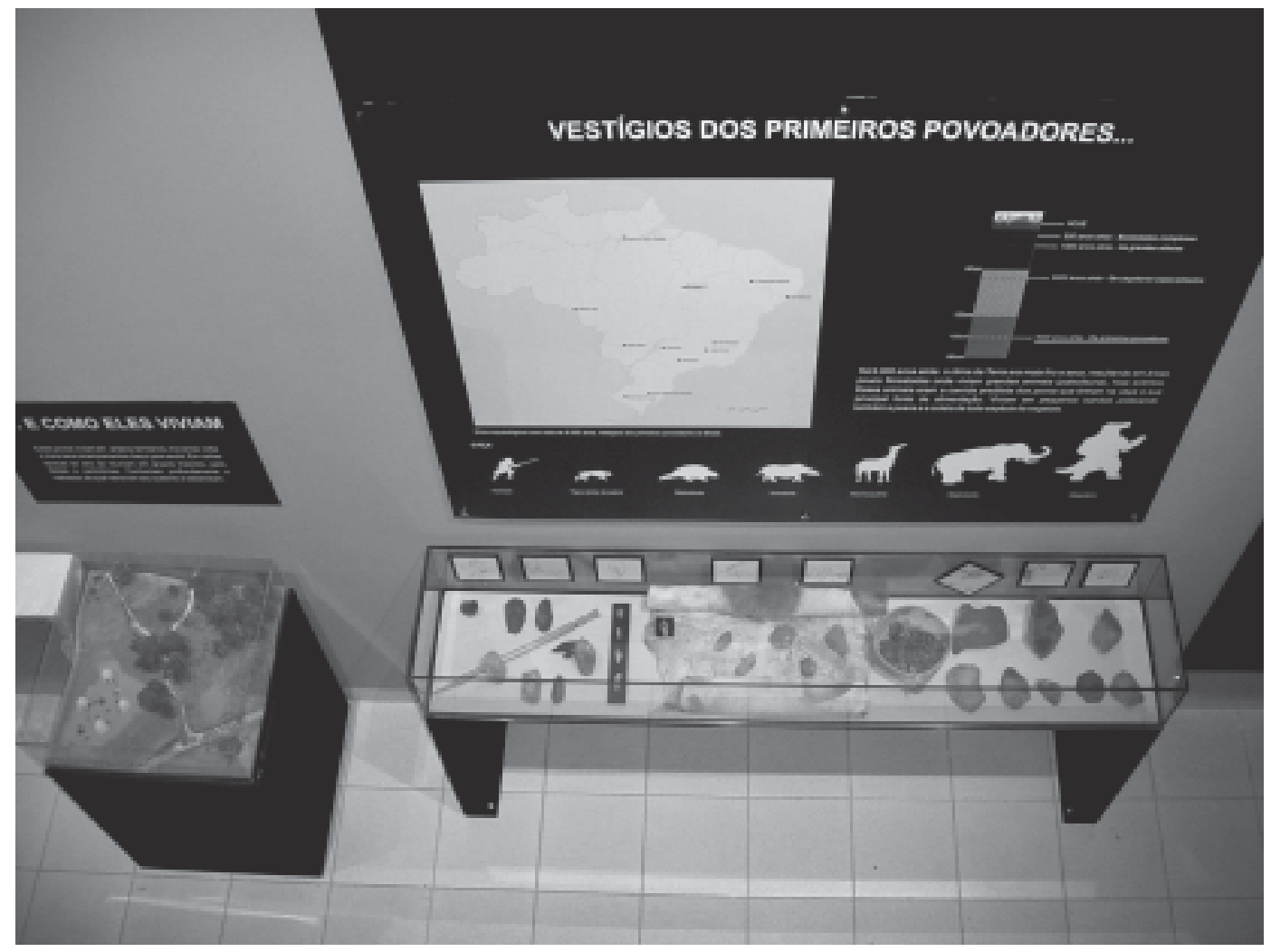

Foto 2 - Os Primeiros Povoadores 


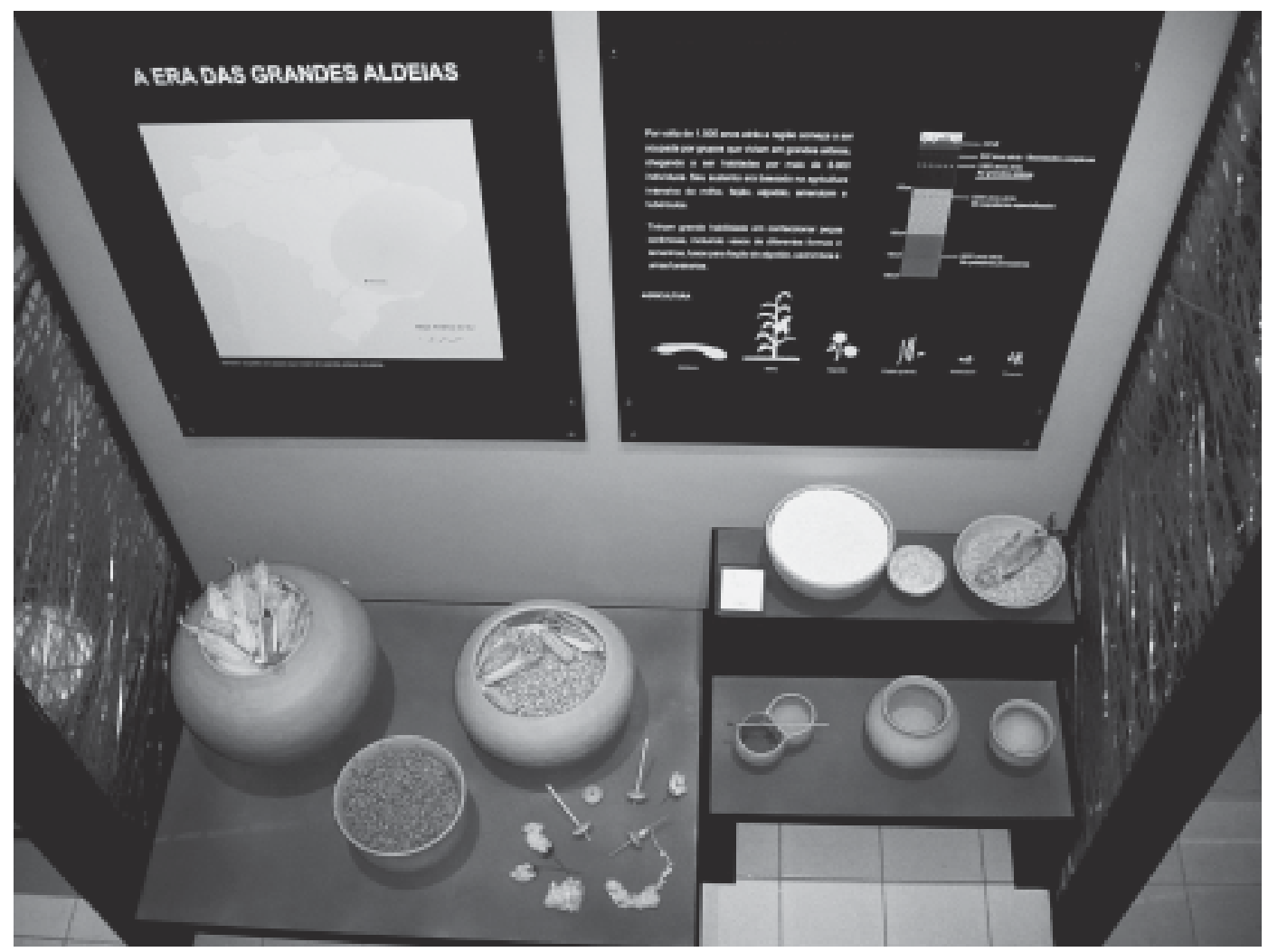

Foto 3 - A Era das Grandes Aldeias

social, (des)(re)territorialização podem ser discutido com o público, ao mesmo tempo em que se exercita a tolerância e a dialógica. Com esse arsenal conceitual o educador pode trabalhar-se e trabalhar com o público na perspectiva de tornarem-se "gourmets" culturais (García Canclini 1999: $2)$, pessoas habilitadas a transitar entre culturas distintas, viajando pelos repertórios simbólicos alheios, saboreando as diferenças e criando pontos de compreensão entre culturas. E por quê não?

0 partido expográfico ${ }^{22}$ escolhido para a exposição foi um "tradicional-modernizado". Tradicional porque apresenta o con-

(22) Quanto à descrição da expografia, vide Cury 2005 e Cury 2005b. teúdo linearmente e as coleções contextualizadamente, utilizando-se de vitrinas e linguagem de apoio convencionais. Há uma relação hierárquica entre artefatos arqueológicos e recursos expográficos. Modernizada porque usa materiais modernos e contrastantes entre si (metal das vitrinas com a mangueira das divisórias) e porque recorre à cenografia como solução expográfica para a escavação (até nas quadras delimitadas pela escavação há vitrinas) e elementos de cenografia para contextualizar, como reconstituições tridimensionais de cerâmicas, em argila e em escala real, e alimentos como milho, mandioca, angus, beiju, coquinhos; ou outros elementos como pele de animal, peças de madeira, algodão, etc.

o partido também orientou para uma exposição ao mesmo tempo sintética e cheia 


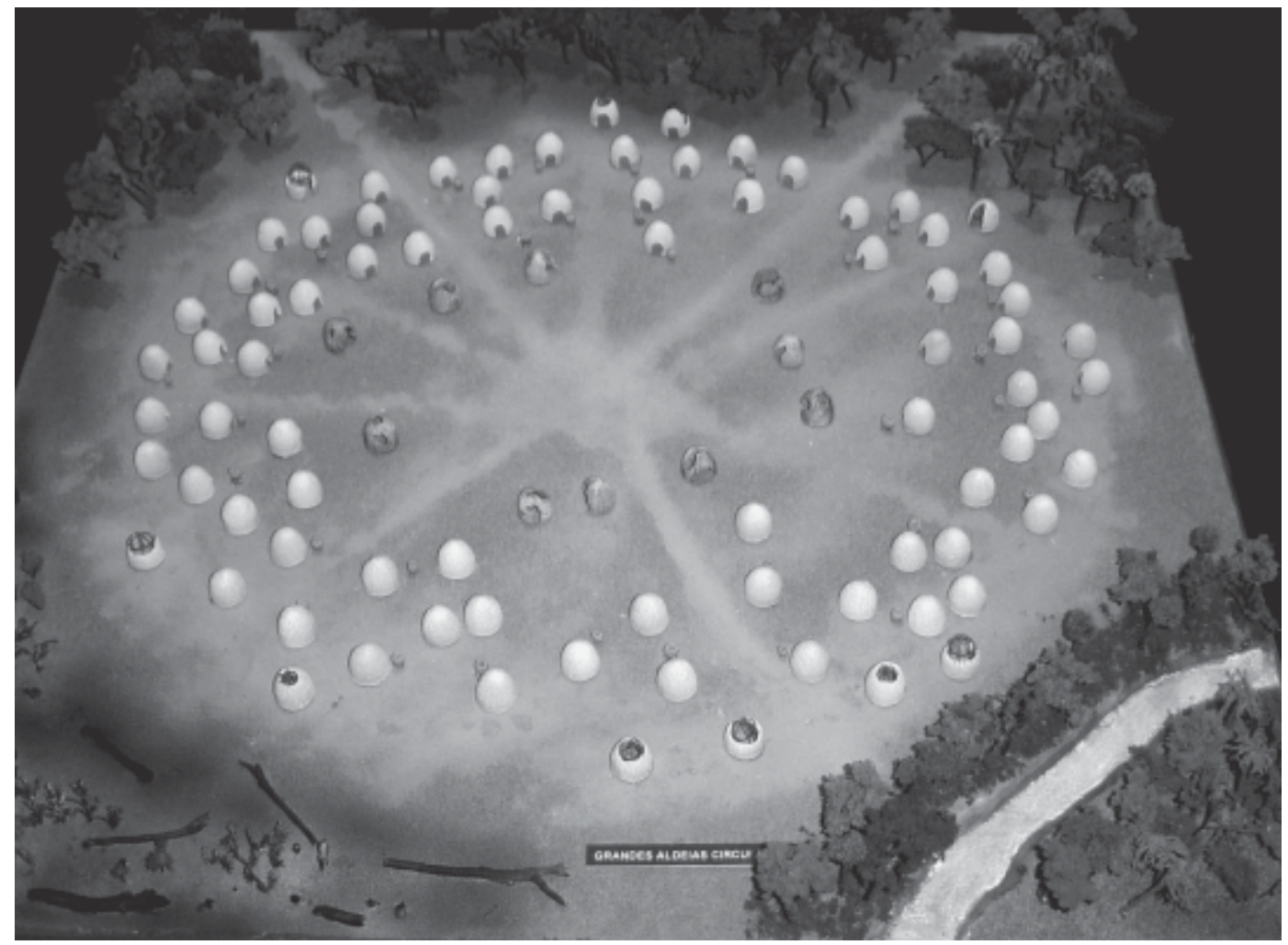

Foto 4 - Maquete da Grande Aldeia Circular de 1500 anos atrás

de detalhes. À primeira vista ela é sintética, com poucos tópicos conceituais, sem acúmulo de objetos, textos, etiquetas. Em um segundo momento os detalhes aparecem, e o que era sintético torna-se detalhado.

Após a inauguração do museu, os mesmos estudantes que participaram da avaliação conceitual foram convidados para visitar a exposição e, em seguida, para avaliá-la. Nesta etapa de pesquisa de recepção os dados foram coletados por observação, técnicas de discussão em grupo e por meio de registros escritos. Os resultados são significativos para nós profissionais de museus, seja para os museólogos, seja para os arqueólogos, pois nos permitem rever todo o processo a partir de um ângulo diferente: 0 público. Certamente que este ponto privilegiado elucida algo mais sobre a nossa práxis, pois nos faz avaliar as nossas posições e reformulá-las. Mas o essencial é que esses resultados nos fazem entender que nos fazemos sujeitos com outros sujeitos.

\section{Considerações finais}

A pesquisa conceitual desenvolvida no contexto do Museu Água Vermelha foi aqui apresentada visando à ampliação da consciência dos profissionais do campo museológico quanto à importância das pesquisas empíricas com 0 público. 0 estudo em questão trouxe à luz aspectos que precisariam ser aprofundados por meio de pesquisas mais amplas e com planejamento interdisciplinar para que os interesses - arqueológicos e museológicos - sejam contemplados a contento para a definição de políticas de ação. Apesar disto, os resultados obtidos foram relevantes para a concepção da 


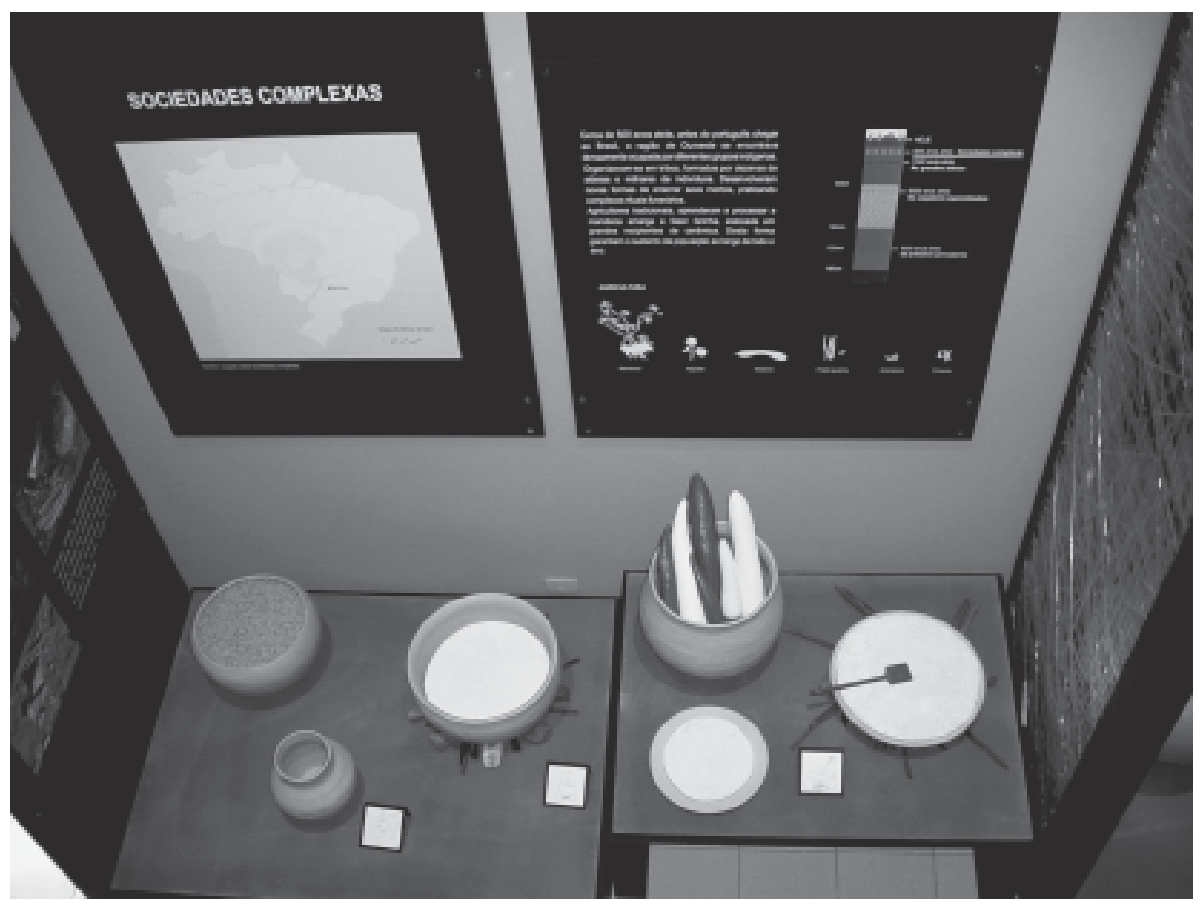

Foto 5 - As Sociedades Complexas

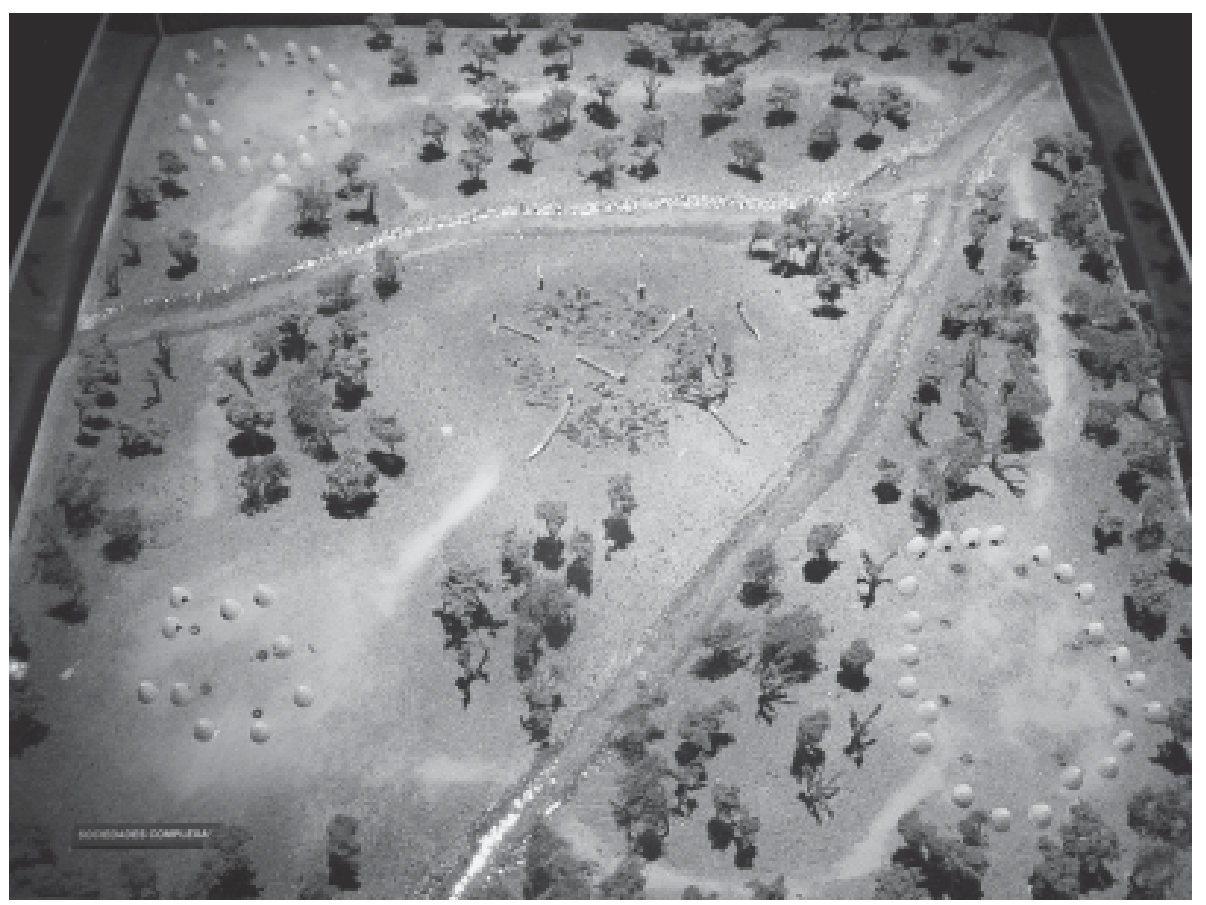

Foto 6 - Maquete das Sociedades Complexas de 500 anos atrás 
exposição Ouroeste: 9 Mil Anos de História e para o exercício de linguagem, o que é fundamental para os museus.

Cabe salientar que a avaliação conceitual é uma face de uma realidade empírica e que associada à avaliação posterior nos permitem conhecer a experiência integral do visitante e a ter uma visão sinérgica dos elementos que compõem a exposição e sua eficácia comunicacional. Ainda, revelam o público como sujeito dos processos museológicos.

Antes de tudo, a pesquisa conceitual nos revelou que há um universo fora dos museus e de nós mesmos que precisa ser explorado, e que este universo é constitutivo da responsabilidade social reservada aos museus e a seus profissionais.

\begin{abstract}
The study presented herein was carried out in 2003 and 2005 at the Água Vermelha Museum of Regional Archeology in Ouroeste, a municipality located in the State of São Paulo, Brazil. The study was the foundation for a doctoral dissertatin entitled Museological Communication - A Theoretic and Methodological View of Reception defended at the School of Communication and Arts of the University of São Paulo. ${ }^{23}$

In this paper we will present certain research findings for discussion. These are partial findings presented in a succinct manner.

The research was theoretically and methodologically based on the areas of museology, communication, and reception. Museology focused mainly expology, expography, and education.
\end{abstract}

Keywords: Archaeological communication. Museological communication. Archaeological exhibition. Heritage education. Museological evaluation.

\title{
Bibliografia
}

CURY, M. X.

2006 Exposição - Concepção, montagem e avaliação. São Paulo: Annablume.

CURY, M. X.

2005 Comunicação museológica - Uma perspectiva teórica e metodológica de recepção. Tese (Doutorado em Ciências da Comunicação) - Escola de Comunicações e Artes da Universidade de São Paulo, São Paulo.

CURY, M. X.

2005b O Museu Água Vermelha. In: Anais. XIII Congresso da SAB: arqueologia, patrimônio e turismo. Campo Grande, MS: Ed. Oeste, 2005.

GARCÍA CANCLINI, N.

2003 A globalização imaginada. Tradução Sérgio Molina. São Paulo: Iluminuras.
GARCÍA CANCLINI, NESTOR.

1999 Gourmets multiculturales. La Jornada Semanal, México, 5 dec. 1999. Disponível em: <http://www.jornada.unam.mx/ 1999/dic99>. Acesso: em: 23 nov. 2002.

MARTÍN-BARBERO, J.

1997 Dos meios às mediações: comunicação, cultura e hegemonia. Tradução de Ronald Polito e Sergio Alcides. Rio de Janeiro: Editora UFRJ.

VASCONCELLOS, C. DE M.; ALONSO, A. C. \& LUSTOSA, P. R.

2000 A abordagem do período pré-colonial brasileiro nos livros didáticos do ensino fundamental. In: Revista do MAE, São Paulo: USP, 10: 231-238.

(23) Supervised by Counselor Dr. Maria Immacolata Vassallo de Lopes 